\title{
The revolutionary impact of the Deep Time concept: Geology's modernity and societal implications
}

\author{
Andrea Fildani ${ }^{1, *}$ \\ ${ }^{1}$ The Deep Time Institute, 13809 Research Boulevard, Suite 500 94952, Austin, Texas 78750, USA
}

The world as we have created it is a process of our thinking. It cannot be changed without changing our thinking.

-Albert Einstein

I propose throughout this short op-ed that Geology, as 1 one of the most recently established core sciences, is the one most at risk of societal misinterpretation precisely because of its innovativeness. The discovery of 'deep time' and the revelation of temporal change were triggered by the advance of geological methodology, which pushed the boundary of the scientific establishment of the time (Rossi, 1979). These discoveries had profound societal implications that are deeply embedded into the scientific progress of the last few centuries but we, at times even geologists ourselves, still struggle to fully embrace the historical aspect of geology, instead accepting it as a 'derivative' of the physical sciences (Dodick and Orion, 2003). By the end of this op-ed I will reason that geology expands on the physical sciences and should be involved at all decision-making levels, and that geologic literacy should become a top priority in terms of public education and policy making.

The core natural sciences: physics, astronomy, chemistry, biology and geology are at different stages of development and societal acceptance, based on time (how long they have been practiced), tangibility (how measurable their questions are), and palatability (how comfortably their concepts fit social norms and trends). The establishment of a scientific field demands codes and definitions, a consensus from a scientific community that shares methods and manuals (Rossi, 1979). These manuals, the foundation for the science, are constantly revised and rewritten, and their existence is essential, in that they constitute and build the science itself.

Copyright (c) 2022 by the SEPM Society for Sedimentary Geology

doi: $10.2110 /$ sedred.2022.1.1

*Corresponding author: afildani@deeptimeinstitute.org
However, the consensus and convergent thinking needed for a science to grow are not always present: they are built hardily and slowly with time. In his work, philosopher of science Paolo Rossi (Rossi, 1979) noticed that the consensus for mathematics and astronomy has been established for a very long time, as these disciplines trace back to early human civilizations (and consequently blend the scientific consensus with religious protocols). Even though geological concepts have peppered human writings since ancient times (i.e., Democritus, Pliny the Elder, Pliny the Younger, and Lucretius are offered as very few examples) and Medieval into Renaissance times (Shen Kuo, Restoro d'Arezzo, and eventually Leonardo da Vinci to mention a few relevant contributors), it was not until the late 17th century and early 18 th century that the formative manuals and the scientific consensus for geology really started to shape up. As a science, geology is a late bloomer.

Its tardiness to the scene reflects the seriousness of the intellectual barriers that geology had to overcome. Geology is conceptually one of the most modern and revolutionary sciences; revolutionary in the strict sense that it caused a complete and dramatic change in our way of thinking. Physics and natural philosophy claimed to deal with the world as it is (in the Newtonian sense, as it was put in movement by God), and so there was no impetus to pose questions about the formation of the world and the beginning of time to such sciences. Geological thinking, on the other hand, gave us tools to understand nature and to reduce risk, but this also added a vulnerability to human existence that required major psychological adjustments for society. Perhaps because of its revolutionary aspect, the consensus for geology has been harder to establish. Indeed, revolutions are unsettling; early geological discourse was shaped by fear. How would institutions and the general public react to the concepts of geology? But what was it about geology that was so unsettling? 


\section{THE GIFT OF 'DEEP TIME' THINKING: A} PROMETHEAN TASK

The introduction of the concept of Deep Time caused a profound transformation in the way we think. This shift required centuries to pass before it could be fully achieved, with the key period being between the late 1600s and late 1700s (Rossi, 1979). In our modern days we fully understand that the history of the universe, the history of Earth, and the history of the human species were built at completely different chronological scales. However, that was not always the case. Natural history and human history were conceived as parallel for a long time, commingled with pre-Christian and then biblical time scales; an Earth not populated by humans was unimaginable and would have been unacceptable if proposed. Early attempts and proposals to detangle human history from natural history and to extend the natural timeframe were rejected as materialistic (e.g., Democritus and Lucretius).

Our modern idea of time, which frames today's scientific knowledge, commenced its maturation toward our current understanding around the second half of the 1600s (Rossi, 1979). In the Western world, there was no reason to challenge pre-Christian stories or biblical teachings. Most people did not question the concept that Earth was created specifically for humans by an act of God (or gods) - they were either too scared to doubt a deity's work or perhaps just so comfortable with the idea that there was no need for change. With bewildering precision, at least for the modern reader's eyes, the Archbishop James Ussher (1581-1656) appointed Sunday, the 23rd of October, 4004 BC as the day when it all started. It is important to note that Ussher was a scholar and practitioner of the historical research known as chronology, which attempted to reconstruct world history by combining biblical and secular texts (Rudwick, 2014). Ussher, as many chronologists of his time, believed that world history had finite limits in the past and the future, with an overall length of exactly six millennia. According to his calculations the end of the world should have been precisely in 1996! So, the women and men of the second half of the 1600s understood Earth's history to be about 6000 years long and with a relatively near end. However, a century later, the women and men of the times knew that Earth was millions of years old with no end in sight.

The leap took a formidable amount of communal effort. Evidence challenging the comfortable setting offered by the Bible and scholarly establishment came from the "shells and fish" (the ones that eventually would be called fossils) that would occasionally be found on mountain trails; these findings triggered curiosity and long debates. Although initially dismissed as meal scraps, some scholars would claim those shells were evidence of the biblical deluge, while others would appeal to philosophical theories (Aristotelian and neo-Platonic) in which fossils were 'organisms' that could form by "spontaneous generation" from nonliving material (Rossi, 1979). According to such theories, this happened inside the Earth.
While the collection and reporting of more complete and intriguing fossils continued, acute observers noticed how these contrasted living species and started to realize that some species were not living anymore, that they had gone extinct. To acknowledge the possibility of extinction was equivalent to recognizing elements of imperfection and incompleteness in God's work. The idea that nature has a history and that the shells document an extinct past started to form in intellectual circles, where nature was not as fixed and immutable as previously believed.

Two figures (savants) gave fundamental contributions to the lively fossils debate of the late 17th century: Nicolas Steno (1638-1686) and Robert Hooke (1635-1703). Steno introduced rigorous criteria to read the sedimentary rocks and recognized that fossils were an important component of these strata, contributing to newer ways to interpret the stratigraphic record. In the anatomical descriptions of the head of a shark washed upon the shores of Tuscany (Fig. 1), Steno recognized the similarities between the teeth and the well-known fossils called Glossopetrae (Steno, 1667). These tongue-shaped objects were petrified and found embedded in rocks. He argued that the Glossopetrae were teeth of much larger sharks from earlier periods in history. At the same time, Hooke firmly distanced himself from the biblical deluge and its followers who tied the presence of fossils to such an event (Steno was still in this camp). Hooke thought this hypothesis was improbable and not supported by evidence. In A Discourse of Earthquakes Hooke disputed the biblical view of Earth's age, proposed the extinction of species, and argued that fossils atop hills and mountains had become elevated by geological processes-quite an unsettling view for his times.

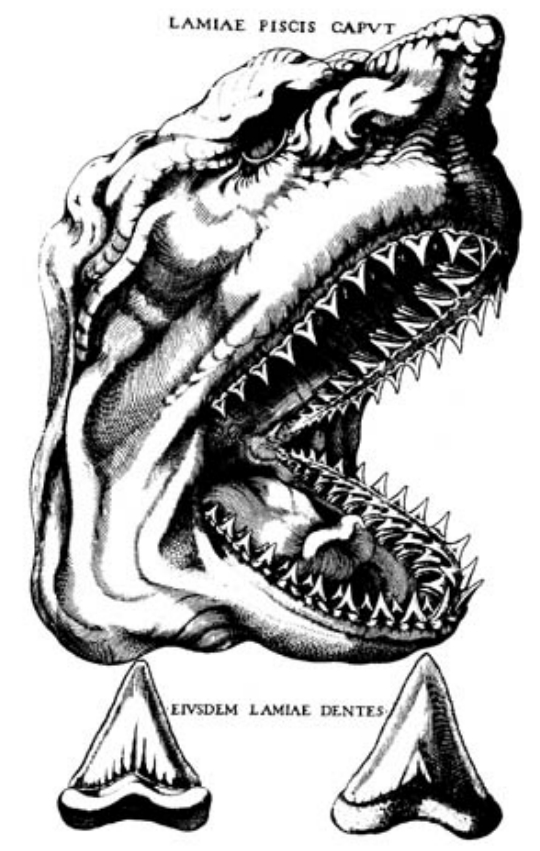

Figure 1 Steno's illustration of a shark's head and its teeth, which appeared in a report published in 1667. 
As intellectuals and philosophers (they called themselves "savants") continued to challenge the reassuring Biblical view, it was in mainland Europe where debates were most vibrant. One of the intellectual catalysts of these times was Georges-Louis Leclerc, later known as Comte de Buffon (1706-1788). During Buffon's lifetime the idea of a 'deeper time' and an older Earth and cosmos had already been diffused throughout intellectual circles. Buffon himself was involved in attempts to calculate a reasonable age for the Earth. He adopted the chronologic tables by Jaques Roger (eventually published in 1778) and timed the cooling of spherical objects of different sizes and material to be scaled up to Earth-size. After many hesitations he settled on a conservative age of 75,000 years, released via a comprehensive thirty-six tome Histoire Naturelle. Having second thoughts, he recalculated the age of Earth to be about three million years, but the new figure was not communicated to the public because he worried about the reader's response. He was convinced that Le Sombre Abîme du Temps (the Abyss of Time) would put the reader in a state of dismay (Rossi, 1979). The debate over Earth's genesis summarized by Buffon, who largely drew on and benefitted from the work of Descartes, Diderot, Thomas Wright, and d'Holbac, was already elevated by Emmanuel Kant in his 1755 Naturgeschichte und Theorie des Himmles where he finally removed the old view of a fixed cosmos and situated humans in their new position: infinite space in front and deep time behind.

James Hutton (1726-1797), considered the "father of modern geology" in the Anglophile tradition, was extremely influential with his geological theory of "past Earths' and in setting the foundational concepts for Uniformitarianism (natural laws and processes operating today operated similarly in the past). Hutton took for granted that time was necessary to achieve the required effect of his theory, as he understood that natural processes, such erosion and deposition, are slow and require time. However, Hutton was a devoted man who never questioned biblical teachings and did not openly engage in the possibility of deep time. Hutton adhered to the Newtonian vision of science, wherein a dividing line exists between science and religion (Rossi, 1979). The question of Earth's formation was firmly outside of science; physics and natural philosophy dealt with the world as it was set in motion by God.

As a good Newtonian, Hutton conceived of Earth as an organized system. He thought researching the origin of the entire system was unnecessary and that nature should be resolved with the context of divine intervention. In this view, the present earth was the result of the destruction of a past earth, requiring equilibrium. Hutton never tackled the age of Earth or its genesis (a relevant difference between him and other European savants like Buffon, Diderot, and $\mathrm{d}^{\prime}$ Holbac) and defended his thesis (Rossi, 1979). Interestingly enough, his effort to distance himself from the origin of Earth and universe and his careful avoidance of any clash with biblical orthodoxy was not enough to make his theories acceptable to the conservative resurgence. The great trauma of the French Revolution caused many to fear the scientific theories for their moral danger and subversive impact (Rossi, 1979); in a way, Hutton was portrayed as more progressive than he ever wanted to be.

Even though Hutton did not help to establish the concept of 'deeper time', he largely benefitted (in popularity) from this new idea, as his theories on Earth's processes and structure were expanded by Charles Lyell (1797-1875), and eventually used by Charles Darwin (1809-1882). It was the requirement of time-to allow the changes to species in the newly forming theory of evolution-that inflamed the debates of the 1800s. Keen observers of nature and sage thinkers as they were, Lyell and Darwin had to face the ghastly attacks of a paladin of biblical tradition, William Thomson (also known as Lord Kelvin, 1824-1907). These attacks were masked with a coat of supposed rigor using mathematical armor (and the ageless dogmatic flair of physics practitioners); the attacks proved to be quite trying for a newborn theory based on observation and conjectural reasoning.

Kelvin tied his physics to a profoundly anti-materialist image of science (Rossi, 1979). For him, astronomy and physics were the essence of science, and he believed geology and biology were on shaky ground, as they could not claim the same rigor of 'his' science. Even though Kelvin's calculations were obscure, difficult to comprehend, and eventually proved wrong, only the discovery of radioactivity would eventually brand his conclusions as outdated (Dodick and Orion, 2003, Rudwick, 2014, Bjornerud, 2018). Ultimately, his insistence on shrinking Earth's age had the same paralyzing effect on evolutionary thinking that the biblical time scale had on the geological contributions of Steno and Hooke (Toulmin and Goodfield, 1965).

\section{SCIENCE AS A COMMUNAL EFFORT}

Many pages have been written about the CopernicanGalilean Revolution as it relocated (relegated?) mankind from the center to the margins of the Universe. Not much has been written about what I would call, with the help of Buffon, the "Abyss of Time" revolution. While there is not much difference between living in the center or elsewhere in the Universe, there is quite a bit of difference between being temporally close to the origin of us (4000+ years) versus having a 'dark abyss' behind. The reorientations of humans, first in space and eventually in time, were indeed major revolutions in the sense that they completely changed our perceptions; both revolutions influenced how we perceive our place in the universe. Although the least frequently mentioned within the history of science is the discovery of deep time (Dodick and Orion, 2003).

I think it is important to reiterate that both revolutions were obtained via the sustained communal efforts of many individuals. Studying the Earth requires a communal effort in the most practical terms: Earth is big and complex, its history is long and unevenly preserved, borders are barriers, and the methods required to study it are many-a 
geologist cannot work isolated in a tower. The discovery of deep time is a clear example of slow-moving, consensusbuilding achievement that involved many scholars: a masterpiece of interdisciplinarity that does not have a single scientific hero behind it. It was indeed a Promethean effort, as the new concept of time freed Earth (and nature) from archaic influences and human fear.

Geology changed the world into its modern-self and, for this reason, it is still receiving Promethean punishments, in the form of dismissiveness by certain circles (Dodick and Orion, 2003, Bjornerud, 2018). For instance, Henry Gee (1999), an editor of Nature, explicitly attacked the scientific status of all hypotheses about the remote past by stating "they can never be tested by experiment, and so they are unscientific... No science can ever be historical." This comment was met with a sharp response by Carol Cleland as she deconstructed the presumed superiority of experimental research by exposing the flawed nature of its methodologies (Cleland, 2001). Geology continues to be accused of not being quantitative enough because it does not fit neatly into the physics or chemistry version of the scientific method and it sometimes cannot be easily described by equations (Dodick and Orion, 2003). This has been difficult to reconcile for those with a narrow view of how science works, often by those who use the same scientific method that formed before consensus integrated the very concept of deep time into our modern understanding of science. Maybe we need a branch of philosophy to improve the scientific method, a Philosophy of Geology.

\section{COMING FULL CIRCLE: THE DEEP TIME THINK- ING FOR FUTURE GENERATIONS}

I have argued that the concept of deep time has been fundamental for us: it has placed humans in the appropriate dimension of a time continuum. It relegated us to a present that was reached only after billions of years of evolution (of the universe, of our planet, and life upon it). As a species $\sim 350,000$ years old, we are not at the tip of this long evolutionary journey, we are just part of a continuum going forward; life will continue its course with or without us. The future of Earth is linked to the Sun's astronomical fate and a few other extra- and intra-planetary scenarios (random celestial events such as meteors will always pose a threat to the Earth biosphere). Our solar system has a finite time to exist, although it is unfathomably long (i.e., billions of years). The ability to conceptually separate timescales allows us to understand nature's timescale and relate it to the human timescale-this is a fundamental step for modern science. Even though evolutionary theory and Darwinism are nowadays labeled as a biology revolution, they have deep roots within the geological understanding of our planet. Darwin, a geologist, obtained rigorous measurements of Earth's age, which was fundamental for his theory. Dobzhansky's essay Nothing in Biology Makes Sense Except in the Light of Evolution is a synthesis addressing the importance of evolution in modern science and society (Dobzhansky, 2013); it is not too bold to say that modern biotechnologies (i.e. vaccines) owe much to the theory of evolution and hence to the unveiling of deep time.

Unfortunately, humans are poorly trained in long-term thinking. Learning about the 'Abyss of Time' has propelled our scientific and related technological advancements (please note, it is not the other way around). Planning for the future by understanding timescales could help us address pressing Earth-scale issues. Maybe our short lifespans make it difficult to see past a couple of generations (though some cultures do seem to have a better feeling for the future generations); we fall for quick turnarounds and market demands (Bjornerud, 2018). We are completely subject to short-term profits, and even our reactions to external solicitations like climate change and sustainability are generating only short-term solutions. Vincent Ialenti, in his book Deep Time Reckoning (Ialenti, 2020), suggests that we learn how to "inhabit a longer now." Long-term issues (like climate change) demand evenkeeled thinking toward long-term solutions and far-future calculations (a reckoning, as Ialenti suggests). The full embrace of any effort in future sustainability is destined to fall short if not fully scaled to a long-term geological frame (Fildani and Hessler, 2021). The revolution of deep time stresses geology's key role in reconstructing Earth's past; responses to planetary challenges like the climate crisis demand the involvement of geology (and geologists) with the understanding that tens of thousands of years should be factored in to any important decisions.

\section{The best prophet of the future is the past. -Lord Byron}

\section{ACKNOWLEDGMENTS}

Prof. Paolo Rossi's "I Segni del Tempo" inspires this short pamphlet-his book is a seminal contribution rediscovered by the author after an Epistolarium with Prof. Emiliano Mutti. Advices and comments from Editor Jennifer Pickering, Angela Hessler, Pietro Sternai, Eduardo Garzanti, and Stefano Dominici helped sharpening the final product.

\section{References}

Bjornerud, M. (2018). Timefulness. Princeton University Press.

Cleland, C. E. (2001). Historical science, experimental science, and the scientific method. Geology, 29(11):987-990.

Dobzhansky, T. (2013). Nothing in biology makes sense except in the light of evolution. The american biology teacher, 75(2):87-91.

Dodick, J. and Orion, N. (2003). Geology as an historical science: Its perception within science and the education system. Science $\mathcal{E}$ Education, 12(2):197-211.

Fildani, A. and Hessler, A. M. (2021). Sustainability without geology? A shortsighted approach. The Sedimentary Record, 19(2):1-4.

Ialenti, V. (2020). Deep time reckoning: How future thinking can help Earth now. MIT Press.

Rossi, P. (1979). I segni del tempo: storia della terra e storia delle nazioni da Hooke a Vico. Feltrinelli Editore.

Rudwick, M. J. (2014). Earth's Deep History: How It Was Discovered and Why It Matters. University of Chicago Press.

Steno, N. (1667). Elementorum myologiae specimen, seu Muscoli descriptio Geometrica, cui accedunt Canis carchariae dissectum caput et Dissectus piscis ex canum genere. Florentiae.

Toulmin, S. and Goodfield, J. (1965). The Discovery of Time. University of Chicago Press. 